\title{
Antioxidant activity of noni juice in heavy smokers
} Mian-Ying Wang*1, M Nawal Lutfiyya ${ }^{2,3}$, Vicki Weidenbacher-Hoper ${ }^{4}$, Gary Anderson ${ }^{5}$, Chen X Su${ }^{6}$ and Brett J West ${ }^{6}$

\begin{abstract}
Address: ${ }^{1}$ Department of Pathology, UIC College of Medicine, 1601 Parkview Avenue, Rockford, IL 61107, USA, ${ }^{2}$ Department of Community Health Sciences, University of Manitoba, Faculty of Medicine, Winnipeg, MB, Canada, ${ }^{3}$ Division of Research and Learning, Winnipeg Regional Health Authority, Winnipeg Manitoba, 200-1155 Concordia Avenue, Winnipeg, MB, Canada, ${ }^{4}$ Department of Family \& Community Medicine, UIC College of Medicine, 1601 Parkview Avenue, Rockford, IL 61107, USA, ${ }^{5}$ Department of Pathology, UIC College of Medicine, 1601 Parkview Avenue, Rockford, IL 61107, USA and ' Research and Development, Morinda Holdings Inc, 333 West River Park Dr, Provo, UT 84606, USA
\end{abstract}

Email: Mian-Ying Wang* - mianwang@uic.edu; M Nawal Lutfiyya - nlutfiyya@wrha.mb.ca; Vicki Weidenbacher-Hoper - VWeide1@uic.edu; Gary Anderson-GaryLA@uic.edu; Chen X Su - chen_su@tni.com; Brett J West - brett_west@tni.com

* Corresponding author

Published: 6 October 2009

Chemistry Central Journal 2009, 3:13 doi:10.1186/1752-153X-3-13

This article is available from: http://journal.chemistrycentral.com/content/3/I/13

(C) 2009 Wang et al
Received: I July 2009

Accepted: 6 October 2009

\begin{abstract}
Background: Noni (Morinda citrifolia) juice has demonstrated antioxidant activity in vitro and in vivo. To evaluate this activity in humans, noni juice from Tahiti (TNJ) was evaluated in a 30 day, doubleblind, and placebo controlled clinical trial with 285 current heavy smokers. Research participants were randomly assigned to three daily treatment groups: $118 \mathrm{~mL}$ placebo, $29.5 \mathrm{~mL} \mathrm{TNJ}$, and II 8 $\mathrm{mL}$ TNJ. Plasma superoxide anion radicals (SAR) and lipid hydroperoxide $(\mathrm{LOOH})$ levels were measured pre and post-intervention.

Results: After 30 days, mean SAR decreased from $0.26 \pm 0.14$ to $0.19 \pm 0.10 \mu \mathrm{mol} / \mathrm{mL}$ in the 29.5 $\mathrm{mL}$ dose group $(P<0.0 \mathrm{I})$ and from $0.26 \pm 0.22$ to $0.18 \pm 0.1 \mathrm{I} \mu \mathrm{mol} / \mathrm{mL}$ in the $118 \mathrm{~mL}$ dose group $(P<0.00 \mathrm{I})$. LOOH levels decreased from $0.53 \pm 0.19$ to $0.40 \pm 0.10 \mu \mathrm{mol} / \mathrm{mL}$ in the $29.5 \mathrm{~mL}$ dose group $(P<0.00 \mathrm{I})$ and from $0.55 \pm 0.2 \mathrm{I}$ to $0.40 \pm 0.14 \mu \mathrm{mol} / \mathrm{mL}$ in the $118 \mathrm{~mL}$ dose group $(P<$ $0.00 \mathrm{I}$ ). No significant reductions in SAR or $\mathrm{LOOH}$ levels were observed in the placebo group.
\end{abstract}

Conclusion: The results suggest an antioxidant activity from noni juice in humans exposed to tobacco smoke, thereby replicating the results found previous chemical and in vivo tests.

\section{Background}

Exposure to cigarette smoke results in the generation of oxygen free radicals that account, in part, for the pathogenesis of smoking related diseases [1-3]. It is estimated that about $10^{17}$ oxidant molecules are present in each puff of cigarette smoke [4]. Smoking results in a subsequent state of oxidative stress, due to the formation of circulating lipid peroxidation products in the blood [5-7], such as lipid hydroperoxides (LOOH), as well as superoxide anion radicals (SAR). Increases in $\mathrm{LOOH}$ and SAR have been measured in the blood following exposure to cigarette smoke [8-10]. The induction of lipid peroxidation is largely due to free-radical reactions involving polyunsaturated fatty acids in biological membranes. The unsaturated bonds undergo autocatalytic or enzymatic processing to form harmful LOOH [11]. The active LOOH quickly decompose to aldehydes and alkenals. All of these are active in DNA binding and are responsible for major endogenous cell damage.

Previous research has established that fruits and vegetables are major sources of dietary antioxidants [12]. Epidemiological studies have demonstrated that consumption of fruits and vegetables may reduce free-radical-induced 
oxidative damage and lipid peroxidation in cigarette smokers [13]. Morinda citrifolia (noni) is an evergreen or small tree that grows in many tropical regions of the world. The fruit of this tree has a history of use as both food and medicine among Pacific Islanders and in Southeast Asia $[14,15]$. Several reports have described various potential health benefits of noni fruit $[16,18]$, including immunomodulation $[19,20]$ and antioxidant activities in vitro and in vivo [21-23]. The European Union-approved form of noni fruit juice from Tahiti (TNJ), has been found to exert an antioxidant effect in human athletes, thereby increasing exercise endurance [24]. This is also the mechanism by which TNJ provided protection against carbontetrachloride-induced liver damage in Sprague-Dawley rats [25]. Hence, TNJ may also mitigate oxidative damage and consequent lipid peroxidation in cigarette smokers. To further evaluate this potential effect, a 30-day, placebocontrolled, double-blinded, and randomized clinical trial was conducted with research participants who were current heavy smokers.

\section{Results and discussion}

There were no significant differences in demographics between the groups. There were no differences in a 1:1 gender ratio, with the ethnic compositions of the groups being primarily Caucasian, 80 - 89\%, and African American, $9.4-18 \%$. The mean age in each group ranged from 37 to $43 \mathrm{yr}$. There was no difference in the mean number of cigarettes smoked each day (26 - 29). During the course of the trial, no adverse health events due to TNJ or placebo ingestion were observed in any of the participants.

Mean pre and post-test SAR and LOOH values are compared in Table 1. No significant inter-group differences were observed in pre-test values. There was no significant change in SAR or LOOH levels in the placebo group. There was a trend for lower post-test SAR levels in both TNJ groups than in the placebo group, although this difference was not statistically significant. However, mean post-test SAR levels in both TNJ groups were significantly lower than their pre-test values. Percent reductions in SAR in the 29.5 and $118 \mathrm{~mL}$ TNJ groups were $26.9 \%(P<0.001)$ and $30.8 \%(P<0.001)$, respectively. The mean post-test

Table I: Serum free-radical levels in current heavy smokers.

\begin{tabular}{|c|c|c|c|}
\hline & Placebo & $29.5 \mathrm{~mL}$ TNJ & I I $8 \mathrm{~mL}$ TNJ \\
\hline \multicolumn{4}{|c|}{ Serum SAR $(\mu \mathrm{mol} / \mathrm{mL})$} \\
\hline Pre-test & $0.23 \pm 0.15$ & $0.26 \pm 0.14$ & $0.26 \pm 0.22$ \\
\hline Post-test & $0.21 \pm 0.17$ & $0.19 \pm 0.10^{*}$ & $0.18 \pm 0.11^{* *}$ \\
\hline \multicolumn{4}{|c|}{ Serum LOOH $(\mu \mathrm{mol} / \mathrm{mL})$} \\
\hline Pre-test & $0.58 \pm 0.22$ & $0.53 \pm 0.19$ & $0.55 \pm 0.21$ \\
\hline Post-test & $0.59 \pm 0.21$ & $0.40 \pm 0.10^{* * *}$ & $0.40 \pm 0.14^{* * *}$ \\
\hline
\end{tabular}

$* P<0.01$, ** $P<0.001$ compared to pre-test values

$* * * P<0.001$ compared to pre-test values and placebo plasma LOOH levels in both TNJ groups were 32\% lower than that of the placebo group $(P<0.001)$. Mean LOOH was reduced in the $29.5 \mathrm{~mL}$ TNJ group by $24.5 \%(P<$ 0.001 , while a $27.3 \%$ reduction was observed in the 118 mL TNJ group $(P<0.001)$.

Gender-specific mean SAR and LOOH levels in the TNJ groups are compared in Table 2. Significant intra-group reductions in SAR and $\mathrm{LOOH}$ occurred in both the males and females of the TNJ groups. The degrees of $\mathrm{LOOH}$ reduction in males and females are essentially the same as observed in the combined gender analysis. A comparison of post-test values revealed no significant differences between males and females, as well as between TNJ dose groups. This latter observation suggests a threshold of antioxidant activity is reached by a daily dose of $29.5 \mathrm{~mL}$.

It is important to note that the placebo contains grape and blueberry juices, the fruits of which have been shown to exhibit antioxidant activities in humans [26]. As such, the placebo also serves as a point of comparison between TNJ and other common fruit juices. The lack of a statistically significant difference in post-test SAR levels between the TNJ groups and the placebo may be explained by the fact that phytochemicals in grapes have the ability to scavenge SAR $[27,28]$. Although the SAR scavenging ability of the grape juice was not great enough to result in significant reductions in heavy smokers, there was enough activity to lower post-test levels in the placebo group to a point where the confidence interval of the mean overlapped those of the TNJ groups. The post-test means of the TNJ groups were, however, significantly less than their pre-test means, as well as the placebo pre-test mean. Therefore, the ability of TNJ to lower SAR in heavy smokers is demonstrated in this trial and is somewhat greater than the grape and blueberry juice blend of the placebo, although only marginally so.

The most significant effect of TNJ in this trial was on mean post-test plasma LOOH concentrations. In both TNJ groups, these were significantly less than pre-test values and the post-test mean of the placebo group. The differential effect on LOOH and SAR sheds some light on the potential target of the antioxidant action of noni juice. SAR is converted to $\mathrm{H}_{2} \mathrm{O}_{2}$ by superoxide dismutase, from which the hydroxyl radical is formed by Fenton-type reduction. The hydroxyl radical triggers chain peroxidation of unsaturated lipids to form LOOH [29]. As smoking generated plasma LOOH levels appear to be more significantly reduced than SAR, it is likely that the hydroxyl radical is a major target of the antioxidant activity of noni juice. Further research is required to elucidate the mechanisms responsible for the preferential lowering of LOOH over SAR. 
Table 2: Serum free-radicals by gender and TNJ dose.

\begin{tabular}{|c|c|c|c|c|}
\hline & \multicolumn{2}{|c|}{ SAR $(\mu \mathrm{mol} / \mathrm{mL})$} & \multicolumn{2}{|c|}{ LOOH $(\mu \mathrm{mol} / \mathrm{mL})$} \\
\hline & $29.5 \mathrm{~mL} \mathrm{TNJ}$ & 118 mL TNJ & $29.5 \mathrm{~mL} \mathrm{TNJ}$ & II 8 mL TNJ \\
\hline \multicolumn{5}{|c|}{ Female } \\
\hline Pre-test & $0.26 \pm 0.14$ & $0.26 \pm 0.24$ & $0.52 \pm 0.23$ & $0.53 \pm 0.16$ \\
\hline Post-test & $0.19 \pm 0.10 * *$ & $0.18 \pm 0.12 *$ & $0.39 \pm 0.11 * * *$ & $0.39 \pm 0.14 * * *$ \\
\hline \multicolumn{5}{|c|}{ Male } \\
\hline Pre-test & $0.25 \pm 0.14$ & $0.26 \pm 0.21$ & $0.53 \pm 0.16$ & $0.57 \pm 0.25$ \\
\hline Post-test & $0.19 \pm 0.10 * *$ & $0.19 \pm 0.12 *$ & $0.40 \pm 0.10 * * *$ & $0.40 \pm 0.11 * * * *$ \\
\hline
\end{tabular}

$* p<0.05, * * p<0.01, * * * p<0.001$

\section{Experimental}

The research protocol of this trial was approved by the Institutional Review Board Committee of the University of Illinois College of Medicine at Rockford, following an ethics review. The trial was conducted in accord with the Declaration of Helsinki and written informed consent was obtained from all participants.

Adult heavy smokers were recruited for enrollment in this study. The inclusion criteria were 18 to 65 years in age, smoker of more than 20 cigarettes per day, a smoking history exceeding one year, and no concurrent use, or use in the previous three months, of prescription medication or antioxidant vitamins. For ethics reasons, fruits and vegetables were not restricted from the diets of the subjects. Both males and females were enrolled in equal proportions.

For this trial noni juice from Tahiti (TNJ) was used (Tahitian Noni International Inc., Provo, Utah, USA). The placebo consisted of a blend of grape and blueberry juices and natural cheese flavor to mimic the flavor of TNJ. Study volunteers were randomly assigned to one of three daily treatment groups: $118 \mathrm{~mL}$ placebo $(\mathrm{n}=42), 29.5 \mathrm{~mL}$ TNJ daily $(\mathrm{n}=121)$, and $118 \mathrm{~mL}$ TNJ $(\mathrm{n}=122)$. Participants and investigators were blinded as to which treatment group each volunteer was assigned to. The male to female ratio of each group was $1: 1$. Those in the $29.5 \mathrm{~mL}$ TNJ group were asked to drink the juice all at once in the morning and on an empty stomach. Those in the other two groups were asked to drink $59 \mathrm{~mL}$ twice daily, once in the morning on an empty stomach and once before bedtime. Additionally, volunteers were asked to drink one cup of water after consuming TNJ. The volunteers were asked to follow this schedule for 30 days.

Upon enrollment, $10 \mathrm{~mL}$ of whole blood was drawn from each volunteer and collected in tubes containing heparin, then centrifuged at $1,500 \times \mathrm{g}$ to obtain plasma for the baseline determination of SAR and LOOH levels. Baseline plasma SAR and LOOH levels represented the initial oxidative status in current smokers. At the conclusion of the 30-day trial, a $10 \mathrm{~mL}$ blood sample was again drawn from each study participant, and plasma SAR and LOOH levels were again determined to assess the impact of TNJ on the oxidative status of current smokers.

The plasma SAR level of subjects was determined by a Tetrazolium Nitro Blue (TNB) assay, as described previously [30]. In this assay, SAR reduces TNB into formazan blue, which absorbs light at $602 \mathrm{~nm}$. An SAR scavenger reduces the absorbance by reacting with SAR, thus preventing formazan blue formation. Also in this assay, $\mathrm{NADH}$ generates SAR under aerobic conditions, with phenazine methosulfate (PMS) as the catalyst.

The plasma $\mathrm{LOOH}$ concentrations were determined by the leucomethylene blue (LMB) assay, as described previously [31,32]. Plasma samples were incubated for $5 \mathrm{~min}$ utes at room temperature with $\mathrm{LMB}$ reagent solution; 1.6 mmol LMB, 0.0055\% hemoglobin (w/v), 1.4\% (v/v) triton X-100, and $8 \%(\mathrm{v} / \mathrm{v})$ dimethylformide in $0.05 \mathrm{M}$ potassium phosphate buffer ( $\mathrm{pH} 5)$. In the presence of hemoglobin, $\mathrm{LOOH}$ oxidizes leucomethylene blue to methylene blue, which absorbs at $660 \mathrm{~nm}$. Plasma LOOH concentration was calculated from the absorbance at this wavelength, against a cumene hydroperoxide generated standard curve.

A power analysis was performed to estimate the number of cases needed to detect a significant effect [33]. The study was designed to compare pre- and post-test data. All analyses were conducted on unpaired cases of each group and included intent-to-treat analysis. The study completion rate among all groups was greater than $73 \%$, with no significant differences between any of the groups (Pearson chi-square test $P>0.5)$. All data were expressed as a mean, \pm standard deviation (SD). To assess the effect of TNJ on plasma SAR and LOOH levels, the averaged means of each group were compared before and after the trial using Student's T-test. Analysis of variance (ANOVA) was used to compare intergroup differences in plasma SAR and $\mathrm{LOOH}$ levels.

\section{Conclusion}

SAR and LOOH levels are biomarkers for degenerative diseases associated with cigarette smoking [34-36]. As noted 
earlier, molecular epidemiologic studies have demonstrated that SAR and LOOH levels in smokers are significantly higher than in nonsmokers [37]. The results of this trial substantiate the antioxidant properties of noni juice observed in vitro and in vivo, as well as demonstrate an effect under conditions of oxidative stress produced by heavy smoking.

\section{Abbreviations}

LMB: leucomethylene blue; LOOH: lipid hydroperoxide; PMS: phenazine methosulfate; SAR: superoxide anion radical; TNB: tetrazolium nitro blue; TNJ: noni juice from Tahiti.

\section{Competing interests}

MYW received funding through a grant made to the University of Illinois College of Medicine at Rockford by Morinda Holdings, Inc., a manufacturer of noni juice. CXS and BJW are employees of Tahitian Noni International, a division of Morinda Holdings, Inc. No competing interests exist for the remaining authors.

\section{Authors' contributions}

MYW generated study design, collected data, performed data analysis, and drafted manuscript. MNL conducted statistical analyses and GA was responsible for IRB preparation and research organization. $\mathrm{VWH}$ was the clinical coordinator, conducted patient interviews, and setup database used to collect and organize data. CXS was involved in analytical method development and data collection. BJW was involved in placebo preparation, data collection and analyses, and in drafting of manuscript. All authors have read and approved the final manuscript.

\section{Acknowledgements}

Summer Jensen, Johnathan Fritz, 'Afa K. Palu assisted in completion of the $\mathrm{LOOH}$ and SAR assays. Funding for this project was provided by Morinda Inc., Provo, Utah, USA.

\section{References}

I. Kalra J, Chaudhary AK, Prasad K: Increased production of oxygen free radicals in cigarette smokers. Int I Exp Path 1991, 72:1-7.

2. Meerson FZ, Kagon VE, Kozolov YP, Belkina IM, Penko A: The role of lipid peroxidation in pathogenesis of ischemic damage and the antioxidant protection of the heart. Res Cardiol 1982, 77:465-485

3. Chow CK: Cigarette smoking and oxidative damage in the lung. Ann NY Acad Sci 1993, 686:289-298.

4. Department of Health and Human Services: Reducing the Health Consequences of Smoking: 25 Years of Progress: A Report of the Surgeon General, DHHS Publication No. (CDC) 89-84 II. Rockville, MD 1989.

5. Morrow JD, Frei B, Longmire AW, Gaziano JM, Lynch SM, Shyr Y, Strauss WE, Oates JA, Roberts LJ: Increase in circulating products of lipid peroxidation ( $\mathbf{F}_{2}$-isoprostanes) in smokers. New Engl J Med 1995, 332: I 198-1203.

6. Dietrich M, Block G, Hudes M, Morrow JD, Norkus EP, Traber MG, Cross EC, Packer L: Antioxidant supplementation decreases lipid peroxidation biomarker $F_{2}$-isoprostanes in plasma of smokers. Cancer Epidemiol Biomarkers Prev 2002, I I:7-13.

7. James RW, Leviev I, Righetti A: Smoking is associated with reduced serum paraoxonase activity and concentration in patients with coronary artery disease. Circulation 2000, I 0 I:2252-2257.

8. Aycicek A, lpek A: Maternal active or passive smoking causes oxidative stress in cord blood. Eur J Pediatr 2008, 167:8I-85.

9. Frei B, Forte TM, Ames BN, Cross CE: Gas phase oxidants of cigarette smoke induce lipid peroxidation and changes in lipoprotein properties in human blood plasma. Biochem J I99I, 277:133-138.

10. Morrison D, Rahman I, Lannan S, MacNee W: Epithelial permeability, inflammation, and oxidant stress in the air spaces of smokers. Am J Respir Crit Care Med 1999, 159:473-479.

II. Altuntas I, Dane S, Gumustekin K: Effects of cigarette smoking on lipid peroxidation. J Basic Clin Physiol Pharmacol 2002, 13:69-72.

12. Wynder EL, Taioli E, Fujita Y: Ecologic study of lung cancer risk factors in U.S. and Japan, with special reference to smoking and diet. Jpn J Res 1992, 83:418-423.

13. Steinmetz KA, Potter JD: Vegetables, fruit, and cancer. II. Mechanisms. Cancer Causes Control I991, 2:427-442.

14. Morton J: The ocean-going Noni, or Indian Mulberry (Morinda citrifolia, Rubiaceae) and some of its "colorful" relatives. Econ Bot 1992, 46:24I-256.

15. West BJ, Jensen CJ, Westendorf J, White LD: A Safety Review of Noni Fruit Juice. J Food Sci 2006, $71:$ R I00-RI06.

16. Wang MY, West BJ, Jensen CJ, Nowicki D, Su C, Palu AK, Anderson G: Morinda citrifolia (Noni): a literature review and recent advances in Noni research. Acta Pharmacol Sin 2002, 23: I| $27-|| 4 \mid$.

17. Ma DL, West BJ, Su CX, Gao JH, Liu TZ, Liu YW: Evaluation of the ergogenic potential of noni juice. Phytother Res 2007, 2I:II00-II0I.

18. Deng S, West BJ, Palu AK, Zhou BN, Jensen CJ: Noni as an anxiolytic and sedative: A mechanism involving its gamma-aminobutyric acidergic effects. Phytomedicine 2007, 14:5 17-522.

19. Palu AK, Kim AH, West BJ, Deng S, Jensen J, White L: The effects of Morinda citrifolia L. (noni) on the immune system: Its molecular mechanisms of action. J Ethnopharmacol 2008, I 1 5:502-506.

20. Hirazumi A, Furusawa E: An immunomodulatory polysaccharide-rich substance from the fruit juice of Morinda citrifolia (noni) with antitumour activity. Phytother Res 1999, 13:380-387.

21. Wang MY, Su C: Cancer preventive effect of Morinda citrifolia (Noni). Ann NY Acad Sci 200I, 952:16I-168.

22. Mohd-Zin Z, Abdul-Hamid A, Osman A: Antioxidative activity of extracts from Mengkudu (Morinda citrifolia L.) root, fruit and leaf. Food Chem 2002, 78:227-23I.

23. Su BN, Pawlus AD, Jung HA, Keller WJ, McLaughlin JL, Kinghorn AD: Chemical Constituents of the Fruits of Morinda citrifolia (Noni) and Their Antioxidant Activity. J Nat Prod 2005, 68:592-595.

24. Palu AK, Seifulla RD, West BJ: Morinda citrifolia L. (noni) improves athlete endurance: Its mechanisms of action. J Medicinal Plant Res 2008, 2:154-I58.

25. Wang MY, Nowicki D, Anderson G, Jensen J, West B: Liver Protective Effects of Morinda citrifolia (Noni). Plant Foods Hum Nutr 2008, 63:59-63.

26. Prior RL, Gu L, Wu X, jacob RA, Sotoudeh G, Kader AA, Cook RA: Plasma antioxidant capacity changes following a meal as a measure of the ability of a food to alter in vivo antioxidant status. J Am Coll Nutr 2007, 26: I70-18I.

27. Vitseva O, Varghese S, Chakrabarti S, Folts JD, Freedman JE: Grape seed and skin extracts inhibit platelet function and release of reactive oxygen intermediates. J Cardiovasc Pharmacol 2005, 46:445-45I.

28. Garcia-Alonso M, Rimbach G, Sasasi M, Nakahara M, Matsugo S, Uchida Y, Rivas-Gonzalo JC, De Pascual-Teresa S: Electron spin resonance spectroscopy studies on the free radical scavenging activity of wine anthocyanins and pyranoanthocyanins. Mol Nutr Food Res 2005, 49: I I I2-III 9.

29. Girotti AW: Lipid hydroperoxide generation, turnover, and effector action in biological systems. J Lipid Res 1998, 39:1529-1542.

30. Nishikimi M, Rao NA, Yagi K: The occurrence of superoxide anion in the reaction of reduced phenazine metosulfate and molecular oxygen. Biochem Biophys Res Commun 1972, 46:849-854. 
3I. Auerbach BJ, Kiely JS, Cornicell JA: A spectrophotometric microtiter-based assay for the detection of hydroperixde derivative of linoleic acid. Anal Biochem 1992, 20 1:375-380.

32. Wang MY, Liehr JG: Identification of fatty acid hydroperoxide cofactors in the cytochrome P450-mediated oxidation of estrogens to quinine metabolites. J Biol Chem 1994, 269:284-29I.

33. Brookes ST, Whitley E, Peters TJ, Mulheran PA, Egger M, Davey Smith G: Sub-group analyses in randomised controlled trials: quantifying the risks of false-positives and false-negatives. Health Technol Assess 200I, 5: I-56.

34. Hecht SS: Cigarette smoking: cancer risks, carcinogens, and mechanisms. Langenbecks Arch Surg 2006, 391:603-613.

35. Shopland DR, Eyre HJ, Pechacek TF: Smoking-attributable mortality in 199I: is lung cancer now the leading cause of death among smokers in the United States? J Natl Cancer Inst 1991, 83:1142-1148

36. International Agency for Research on Cancer: IARC Monographs on the Evaluation of the Carcinogenic Risk of Chemicals to Humans. Tobacco Smoking, Lyon 1986, 38:

37. Vaart $\mathrm{H}$ van der, Postma D, Timens $\mathrm{W}$, Ten $\mathrm{H}$ : Acute effects of cigarette smoke on inflammation and oxidative stress: a review. Thorax 2004, 59:7|3-72I.

\footnotetext{
Publish with ChemistryCentral and every scientist can read your work free of charge

"Open access provides opportunities to our colleagues in other parts of the globe, by allowing

anyone to view the content free of charge."

W. Jeffery Hurst, The Hershey Company.

- available free of charge to the entire scientific community

- peer reviewed and published immediately upon acceptance

- cited in PubMed and archived on PubMed Central

- yours - you keep the copyright

Submit your manuscript here:

http://www.chemistrycentral.com/manuscript/

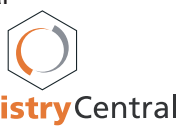

